\title{
S-wave velocity structure beneath Changbaishan volcano inferred from receiver function*
}

\author{
Jianping $\mathrm{Wu}^{\star}$ Yuehong Ming Lihua Fang Weilai Wang \\ Institute of Geophysics, China Earthquake Administration, Beijing 100081, China
}

\begin{abstract}
The S wave velocity structure in Changbaishan volcanic region was obtained from teleseismic receiver function modeling. The results show that there exist distinct low velocity layers in crust in volcano area. Beneath WQD station near to the Tianchi caldera the low velocity layer at $8 \mathrm{~km}$ depth is $20 \mathrm{~km}$ thick with the lowest S-wave velocity about $2.2 \mathrm{~km} / \mathrm{s}$. At EDO station located $50 \mathrm{~km}$ north of Tianchi caldera, no obvious crustal low velocity layer is detected. In the volcanic region, the thickness of crustal low velocity layer is greater and the lowest velocity is more obvious with the distance shorter to the caldera. It indicates the existence of the high temperature material or magma reservoir in crust near the Tianchi caldera. The receiver functions and inversion result from different back azimuths at CBS permanent seismic station show that the thickness of near surface low velocity layer and Moho depth change with directions. The near surface low velocity layer is obviously thicker in south direction. The Moho depth shows slight uplifting in the direction of the caldera located. We consider that the special near surface velocity structure is the main cause of relatively lower prominent frequency of volcanic earthquake waveforms recorded by CBS station. The slight uplifting of Moho beneath Tianchi caldera indicates there is a material exchanging channel between upper mantle and magma reservoir in crust.
\end{abstract}

Key words: Changbaishan, volcano, seismic velocity structure, receiver function

CLC number: P315. $3^{+} 1$ Document code: A

\section{Introduction}

Changbaishan Tianchi volcano is located on the border between Jilin province, northeastern China and North Korea. In recent 1000 years Changbaishan volcano erupted several times and the eruption around 1200 is considered to be one of the largest eruption in the world since the last 2000 years. According to historical records and geological investigation, two small to medium-sized eruptions occurred in 1668 and 1702 and a small-scale phreatomagmatic eruption occurred in 1903 in Changbaishan volcano (Liu et al, 1992; Wei et al, 2004). Several studies show that Changbaishan volcano still has eruption danger (e.g., Liu et al, 1992).

Changbaishan volcano is one of the several volcanoes that might be related to the deep earthquake zone in the world. In the east of Japan Island, the Pacific plate is subducting along the western Pacific margin at the speed of $9.5 \mathrm{~cm} / \mathrm{a}$, and forms a $1100 \mathrm{~km}$ wide seismic zone from Japan Island to Hunchun and Mudanjiang

\footnotetext{
* Received 12 May 2009; accepted in revised form 14 July 2009; published 10 August 2009.

• Corresponding author. e-mail: wjpwu@cea-igp.ac.cn
}

region in Northeast China. The nearest distance from Changbaishan to the deep seismic zone is about $260 \mathrm{~km}$. Figure 1a shows epicentral distribution of earthquakes with magnitude larger than 5.0 reported by $1964-1998$ ISC Bulletins and 1999-2003 China Seismic Network Bulletins. Figure $1 \mathrm{~b}$ shows the distribution of focal depths along longitude. The figure clearly shows that the western Pacific plate is subducting westwardly with the angle of approximately $30^{\circ}$, and reaches to $600 \mathrm{~km}$ depth beneath Chinese mainland. Along oceanic plate subduction zone, it often forms a volcanic island arc mostly $150-200 \mathrm{~km}$ away to the subduction trench. The magma is mainly generated by partial melting caused by dehydration of subducted lithosphere which may lower the solidus temperature of overlaying rocks. The volcanic isotope studies in Changbaishan shows that although quite different from volcanic island arc, volcanic magma in this region is obviously affected by subduction of oceanic crust (Xie and Wang, 1988; Liu et al, 1998).

According to the seismic data recorded at station CBS, the seismicity in Changbaishan volcano increased significantly from 2002 to 2005 (Figure 2). GPS meas- 
urement and leveling results show obvious horizontal expansion and surface uplifting during that period. 15 temporal seismic stations were deployed to monitor seismic activity in Changbaishan volcano in summer
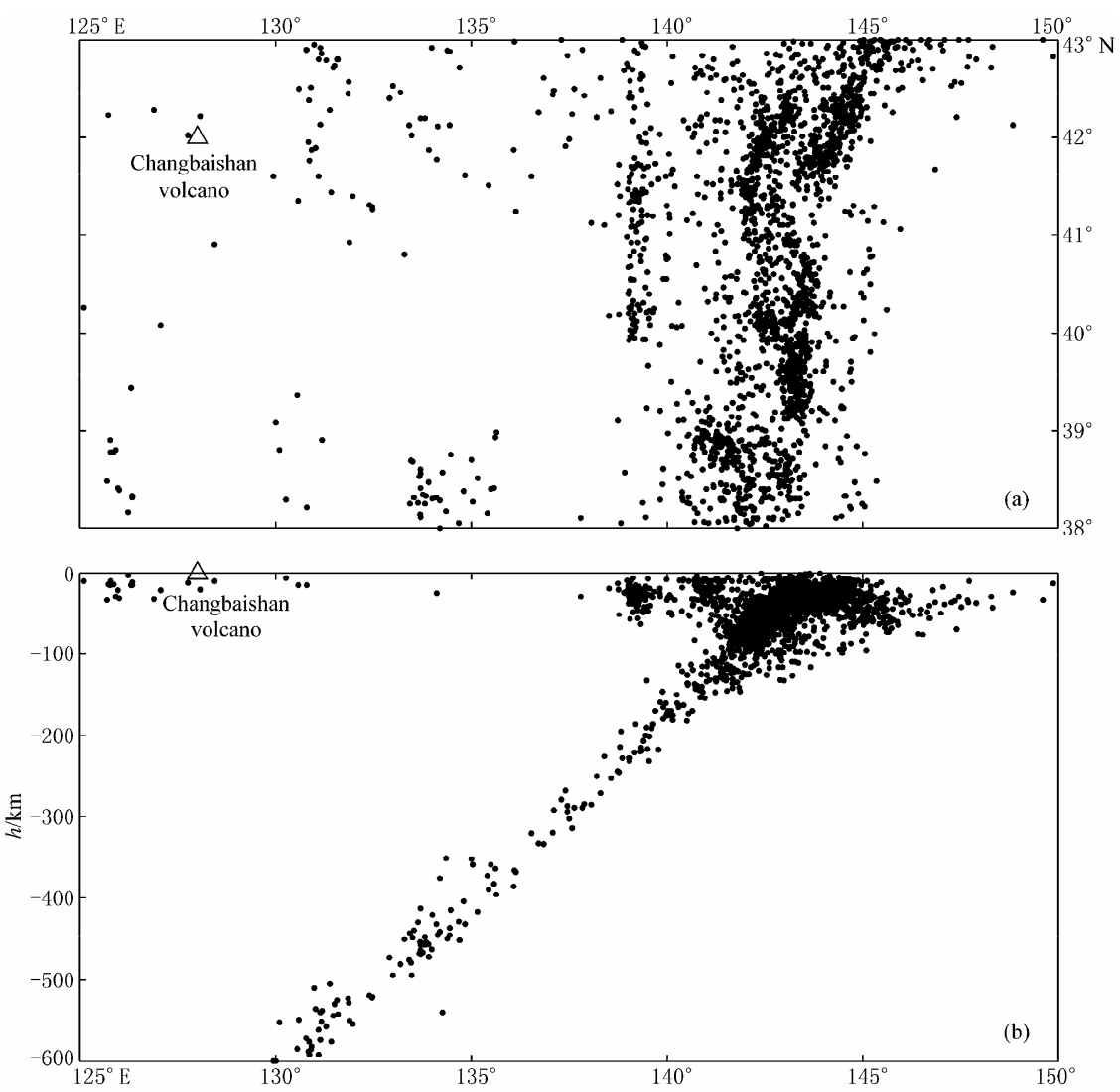

Figure 1 Map of west Pacific Benioff seismic zone and location of Changbaishan volcano. (a) Distribution of epicenters with magnitude larger than 5.0; (b) Distribution of focal depths and location of Changbaishan volcano.
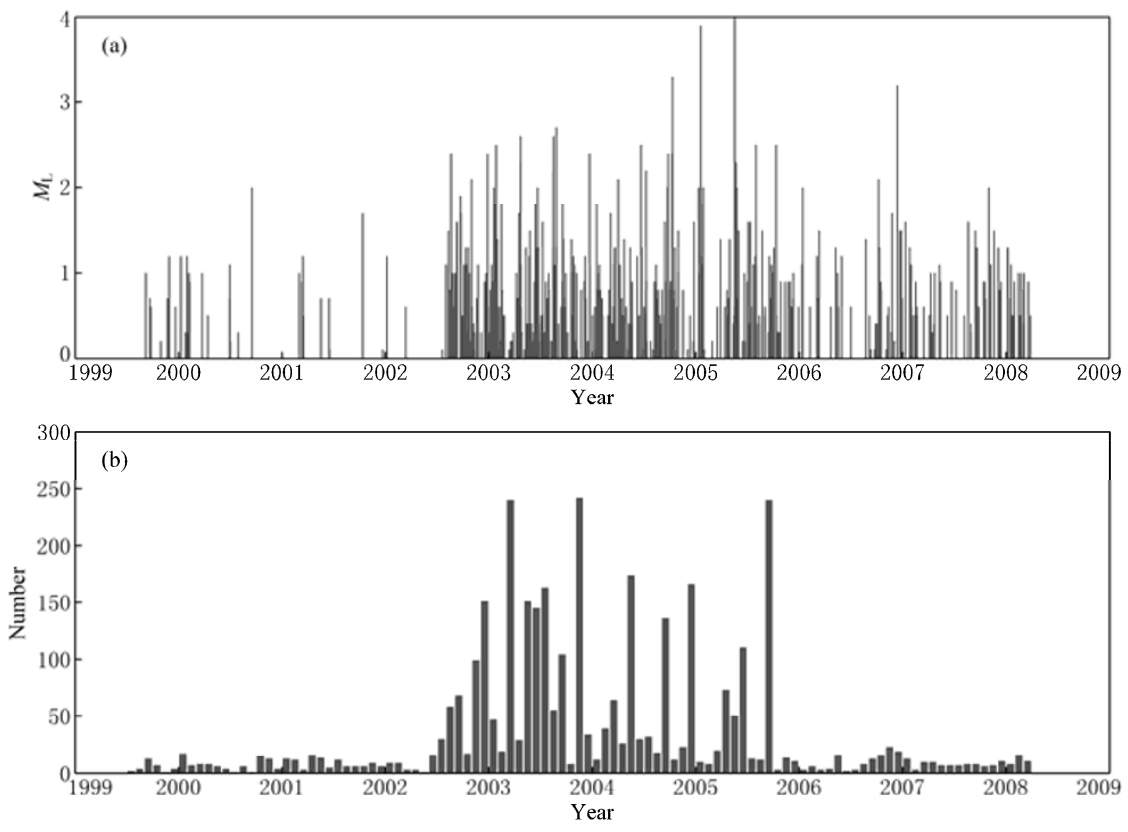

Figure 2 Map of seismicity in Changbaishan Tianchi volcano. (a) Magnitude-time diagram observed by CBS station; (b) Monthly number of earthquakes recorded by CBS station. 
seasons from 2002 to 2005. A lot of micro-earthquakes were detected by the temporal seismic network (Wu et al, $2005,2007)$. The temporary seismic stations also recorded many teleseismic events, which provide us an opportunity to study deep velocity structure in Chanbaishan volcano region

In recent two decades, receiver function has been widely used in investigation of crust and upper mantle velocity structure (Owens et al, 1984; Liu et al, 1997; $\mathrm{Wu}$ and Zeng, 1998, Wu et al, 2001). Receiver function is sensitive to vertical velocity variation, especially to the low velocity caused by partial melting or high temperature in crust. For example, Darbyshire et al (2000) found an extremely S-wave low velocity layer (2.0-2.5 $\mathrm{km} / \mathrm{s}$ ) at $10-15 \mathrm{~km}$ depth in crust beneath Krafla volcano in northeastern Iceland. Hetland et al (2004) studied the S-wave velocity structure in Changbaishan and its surrounding region by using receiver function method, and found low velocities in the middle crust in the region of the main volcanic edifice. However, only one seismic station with distance less than $40 \mathrm{~km}$ from Changbaishan Tianchi volcano was used in their study, the detail variation of S-wave velocity in volcanic region was not obtained. In this paper, teleseismic data from ten temporal seismic stations and one permanent seismic station deployed in volcanic region were used to study S-wave velocity structure in Changbaishan volcanic region.

\section{Data and method}

In summers of 2002, 2003 and 2005, 15 mobile broadband seismometers were deployed in Changbaishan Tianchi volcano (Figure 3) to monitor volcanic seismic activity. Each mobile seismograph has three component sensors (BKD-2) and one 24-bit data logger (ACE-1). Seismometer has a relatively flat response to ground velocity within $0.05-30 \mathrm{~Hz}$ frequency band. Each channel records in 125 samples per second and uses GPS receiver for timing. Due to the steep terrain, forests cover below $2000 \mathrm{~m}$ in elevation and the border between two countries, temporary seismic stations were mainly deployed along roads in three places, the north, east and southwest areas of Tianchi volcano. Most of stations were located within $5 \mathrm{~km}$ away from the boundary of Tianchi Lake, only 3 to 4 stations were deployed $15 \mathrm{~km}$ away from the eastern boundary and EDO station was deployed $50 \mathrm{~km}$ away to the north of the caldera. The permanent seismic station CBS in Changbaishan volcano was deployed in July 1999. The seismograph has flat responses to the ground motion velocity from 0.05 to $20 \mathrm{~Hz}$ and uses GPS receiver for timing. Temporary station HSZ is located in the same cave as station CBS.

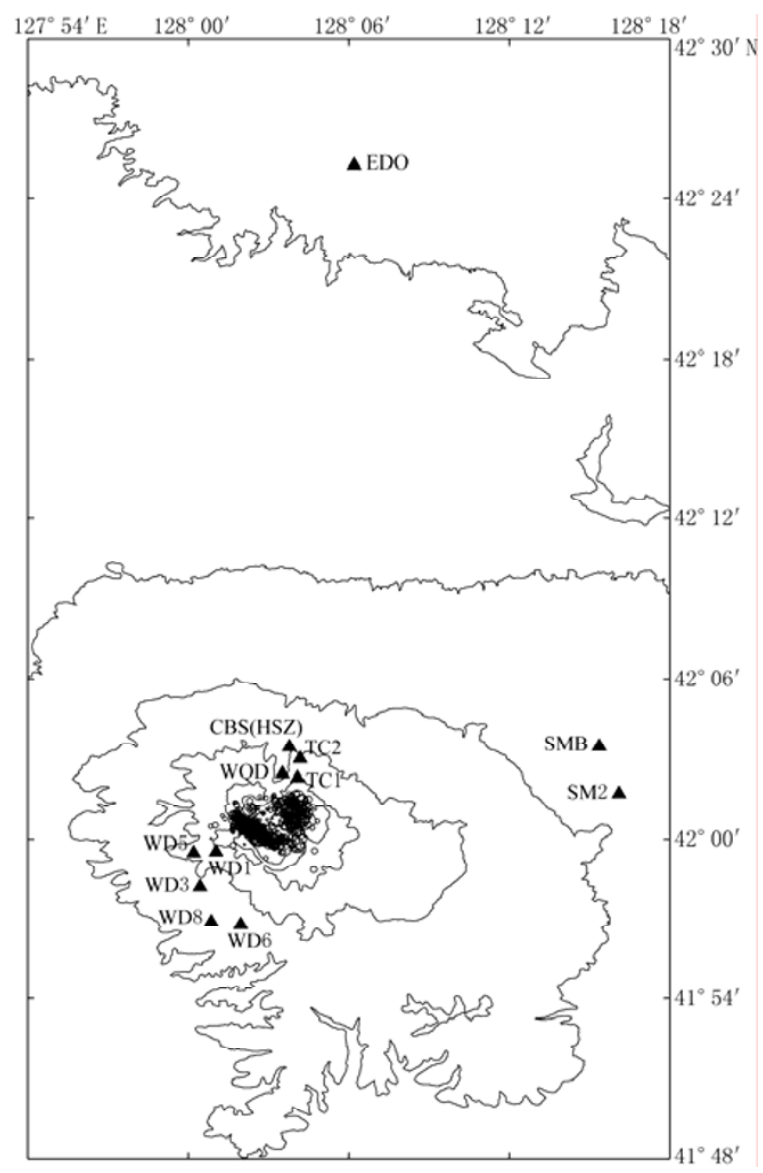

Figure 3 Topographic map of the Changbaishan volcano showing locations of seismic stations (solid triangles) and epicenters (open circles) near the caldera. The level contours are shown for every $400 \mathrm{~m}$.

During temporal seismic monitoring period many teleseismic events were recorded by broadband seismometers. Figure 3 shows seismic stations and Figure 4 shows the epicenters of earthquakes used in this study. In calculation of $\mathrm{P}$ wave receiver function, the vertical component is considered as the original wave, which contains the effect of source and travel path. The receiver functions are obtained by the deconvolution of vertical component from radial and transverse components. The receiver function largely eliminates the influence of source time history and travel path, and it is very sensitive to the P-S converted waves in the velocity structure beneath the station. Many methods are developed to solve the problem of the instability of deconvo- 
lution in calculating the receiver function. In order to solve this problem in frequency domain, the 'water level' is usually introduced to eliminate the instability of the spectrum division. In this paper, we choose maximum entropy spectrum deconvolution method to calculate the teleseismic receiver function (Wu and Zeng, 1998). Figure 5 shows individual receiver functions and stacked receiver functions of WD1 station.

The reflectivity method (Kennent, 1983) is used to calculate synthetic receiver function. The differential seismograms were calculated by changing S-wave velocity in the same layer with difference of $0.005 \mathrm{~km} / \mathrm{s}$. The layer thickness is fixed to $2 \mathrm{~km}$ in crust and upper mantle beneath the seismic station, except $1 \mathrm{~km}$ thick in first two layers near surface. Both S-wave velocity and $v_{\mathrm{P}} / v_{\mathrm{S}}$ are estimated in receiver function waveform fitting. The $v_{\mathrm{P}} / v_{\mathrm{S}}$ in each layer is constrained within 1.6-2.1. The density $\rho$ is calculated using the empirical formula

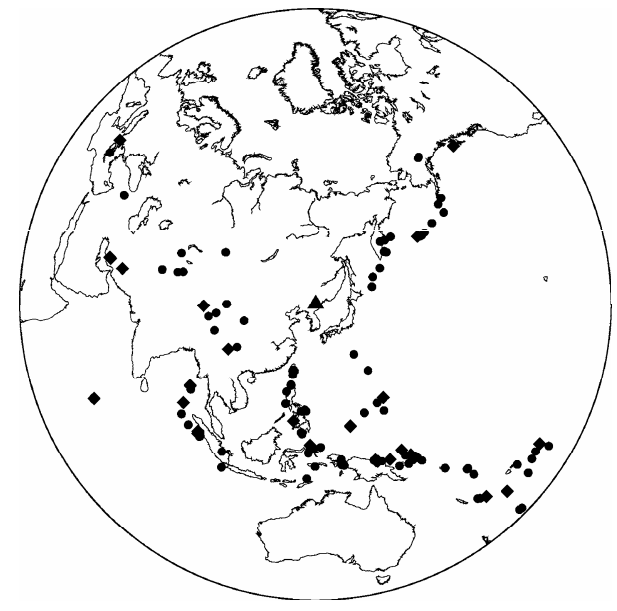

Figure 4 Epicenters of seismic events used in this study. Solid circles denote earthquakes recorded by CBS station during 2002-2005. Solid rectangular represent events recorded by temporal seismic stations.
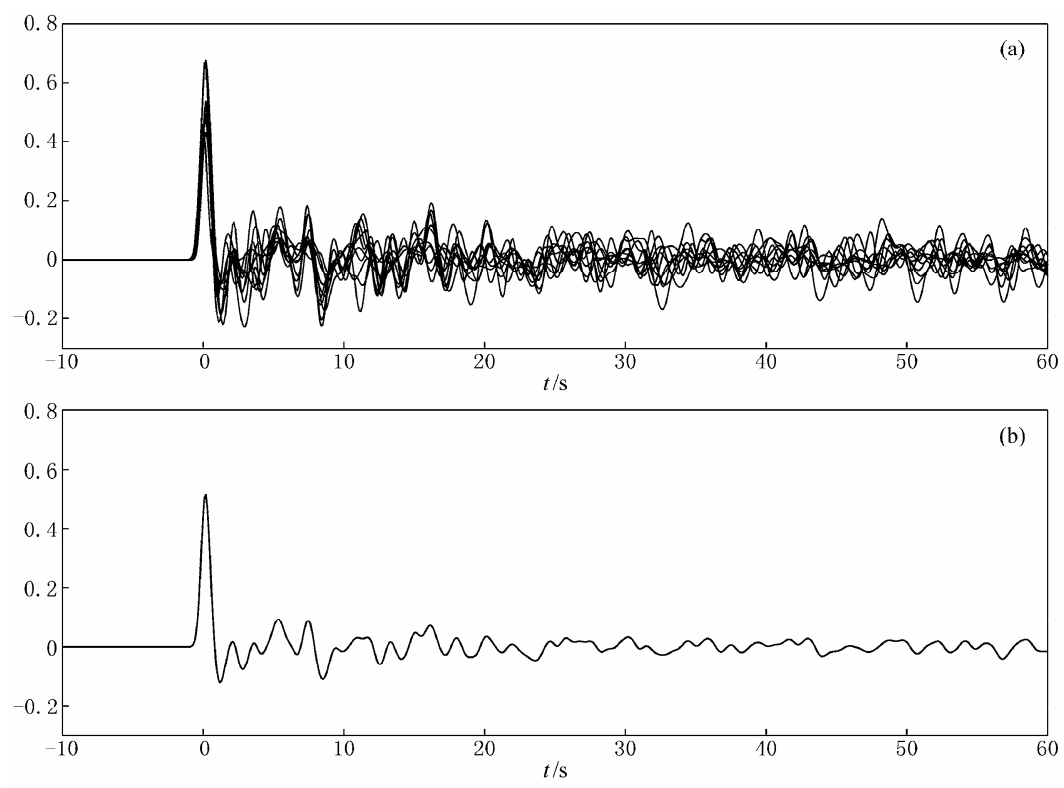

Figure 5 Stacked receiver functions of WD1 station calculated from events with similar distances.

(a) Receiver functions from events around $47^{\circ}$ distance; (b) Stacked receiver function.

$\rho=0.32 v_{\mathrm{P}}+0.77$. By introducing the smooth limitation of model and trade off between waveform fitness and smooth of model, the reasonable $\mathrm{S}$ wave velocity structure can be obtained.

\section{Results}

Figure 6 shows the S-wave velocity structures beneath seismic stations and the synthetic waveforms best fitting the data. At WQD station, the S-wave velocity decreases obviously at $8 \mathrm{~km}$ depth, and the lowest velocity is about $2.2 \mathrm{~km} / \mathrm{s}$ at $16 \mathrm{~km}$ depth. The thickness of this low velocity layer reaches about $20 \mathrm{~km}$. Similar to the WQD, the S-wave velocity structure at all other seismic stations near to Tianchi caldera, such as HSZ, WD1,WD5 and WD3, shows distinct low velocity layer in crust, although the thickness and the lowest value are slightly different. At WD6 and WD8, S-wave low velocity layer is not obvious in crust. Beneath the EDO station, about $50 \mathrm{~km}$ north to Tianchi caldera, no obvious 
low velocity appears in crust. Beneath stations SM2 and SMB at east of the caldera the shallow S-wave velocity is relatively lower, but no obvious low S-wave velocity layer is found in crust. The Moho beneath seismic stations near caldera shows a smooth velocity gradient zone, not a sharp discontinuity.

CBS is the only permanent seismic station near Changbaishan volcano before 2007. Since established in 1999, many teleseismic events have been recorded by the station. Figure 7 shows the receiver functions at different back azimuths. It can be seen that receiver functions change obviously with back azimuth. At $\sim 200^{\circ}$ back azimuth, a clear phase with positive amplitude follows just after the direct $\mathrm{P}$ wave and forms a V-shape on both sides. It indicates that there is an obvious shallow velocity interface in south of the station, and the depth of the interface decreases in both sides. The phase arrived at $5 \mathrm{~s}$ after direct $\mathrm{P}$ wave is corresponding to convert P-S wave at Moho. It is clear that the smallest relative arrival time of this phase appears around back azimuth of $200^{\circ}$. It indicates that Moho interface uplifts slightly in that direction. In the crust, there are two obvious sets of positive phases in receiver functions. The relative arrival times are also early in south than that in north, which indicates the interfaces within crust slightly uplift in south. Within $160^{\circ}-230^{\circ}$ back azimuth directions, the amplitude of receiver functions is mainly negative before the arrival of P-S converted wave at Moho. It may be caused by either the shallow low velocity layer or the low velocity layer in the middle crust. It is difficult to distinguish them only from waveforms.
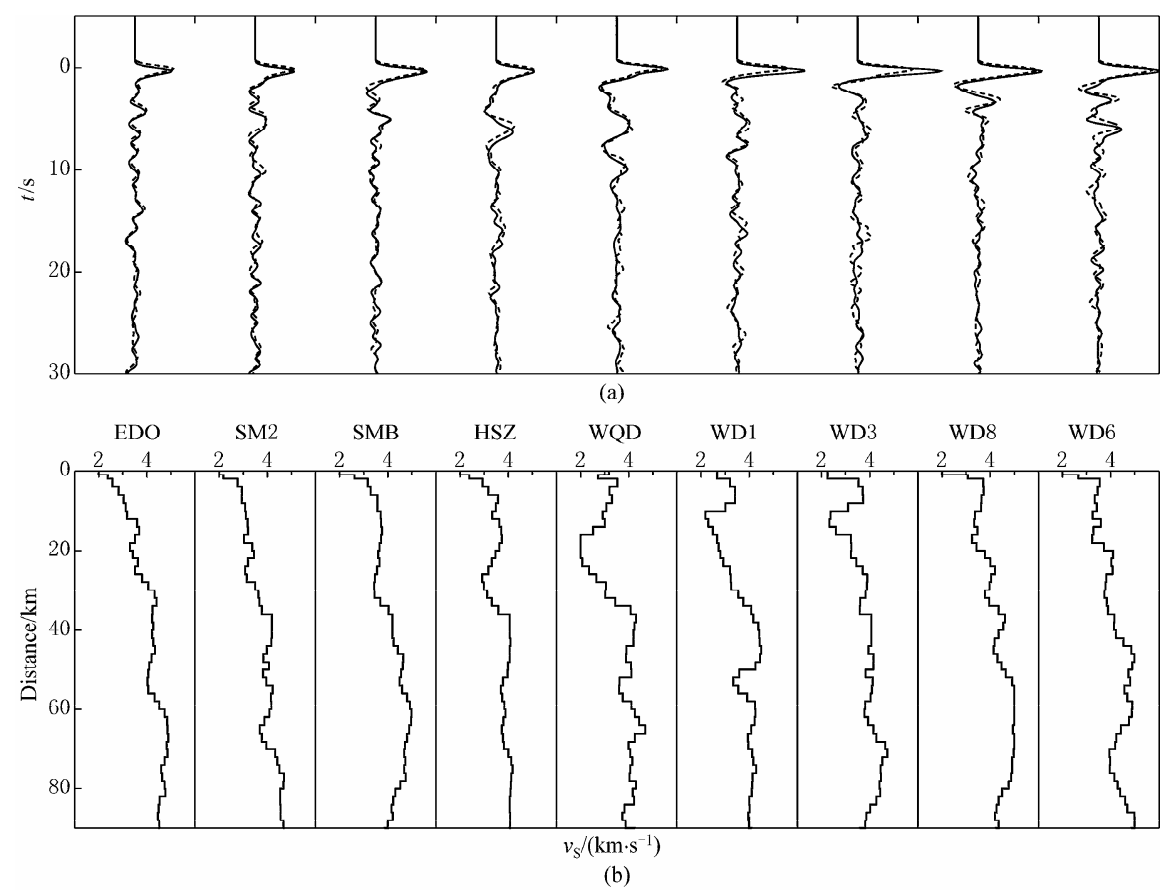

Figure 6 Receiver functions and S-wave velocity structures beneath seismic stations. (a) Observed (black solid lines) and synthetic (dashed lines) receiver functions; (b) Inverted S-wave velocity structure for different seismic stations.

We select 22 receiver functions from different directions to estimate horizontal variation of velocity structure in crust. In each direction, receiver functions with similar epicentral distances are stacked to form the averaged receiver function to improve the signal-tonoise ratio. Considering the possible large velocity variation near surface, the medium from the surface to 4 $\mathrm{km}$ depth is divided into eight layers, the thicknesses are $0.1,0.2,0.3,0.4,0.5,0.5,1.0$ and $1.0 \mathrm{~km}$, respectively. Below $4 \mathrm{~km}$ depth, each layer is $2 \mathrm{~km}$ thick.
Figure 8a shows the comparison between observed and the synthetic receiver functions at different back azimuth directions. Each observed receiver function is well fitted. Figure $8 \mathrm{~b}$ shows the inverted S-wave velocity models. At $150^{\circ}-240^{\circ}$ back azimuth, the near surface low velocity layer is about $4-5 \mathrm{~km}$ thick. The thickness of shallow low velocity layer in direction of east and west is much thinner, about 1 to $2 \mathrm{~km}$ thick. All inversion velocity models at different back azimuths contain obvious low velocity layer in crust at CBS station. The 
lowest S-wave velocity of the layer appears in south direction. The horizontal range of low velocity body is larger at $12-22 \mathrm{~km}$ depth and much smaller at shallow depth. The top depth of the low velocity body is about 9 $\mathrm{km}$ at back azimuth of $180^{\circ}$, and gradually increases to both sides. The depth of Moho shows a similar characteristic, shallower in south and deeper in both sides. This result is consistent with the conclusion of slightly uplift of Moho from waveform analysis of receiver functions in different directions. It needs to point out that although the observed receiver functions in different directions can be fitted properly, the inversion method is still one-dimensional. The more reliable inversion results need to use forward calculation based on three -dimensional structure, but such methods may still have difficulties by lack of enough information.

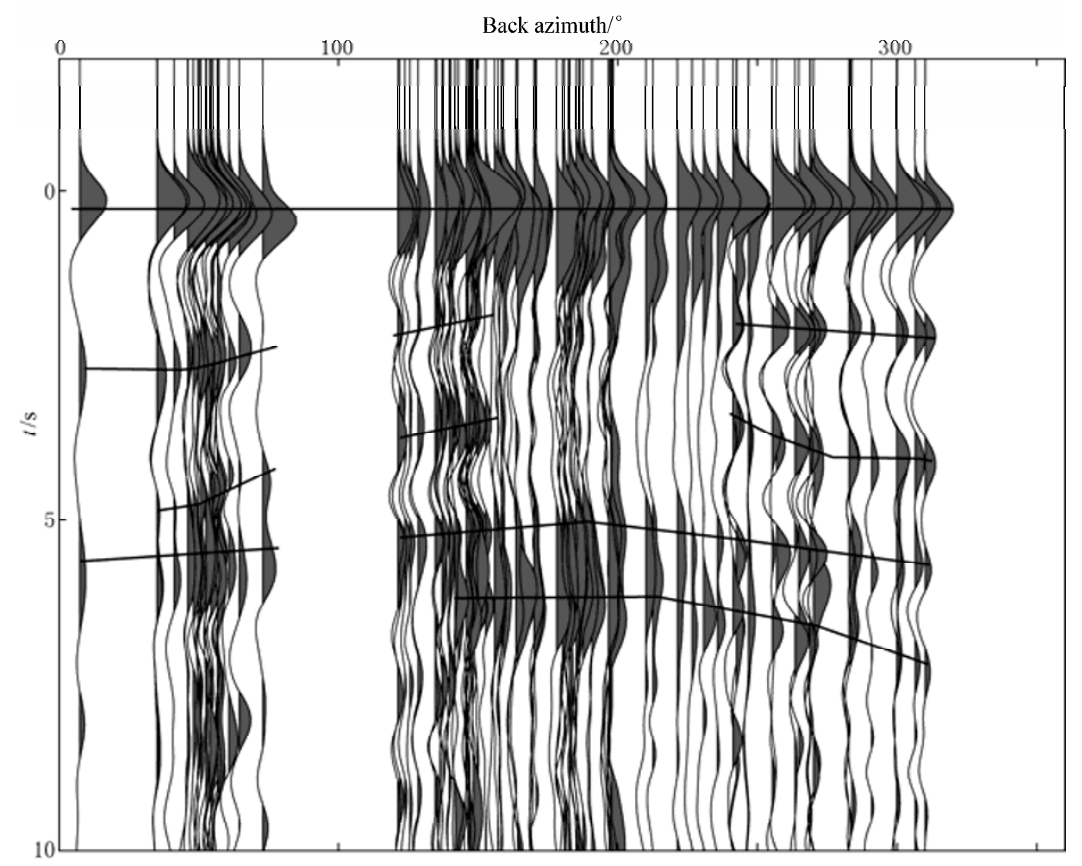

Figure 7 Receiver functions from different back azimuth directions at CBS station. Gray areas represent positive phase. Solid lines are drawn manually to highlight the time shift trends of phases.

\section{Discussions}

Overall, the low velocity layers in the crust are widespread near Changbaishan volcano, the thickness of low velocity layers increases and lowest velocity decreases with shorter distance to the caldera. Tang et al (2001) found two high conductive bodies at depths of $12-40 \mathrm{~km}$ in north and east of the Tianchi lake. Zhang et al (2002) considered that the low $P$ wave velocity magma system in crust can be divided into three depth levels from seismic sounding investigation. The largest one is located in 9-15 km depth with $90 \mathrm{~km}$ long in north-south and $30 \mathrm{~km}$ wide in east-west, which is considered as main layer storing magma. The lowest $\mathrm{P}$-wave velocity is about $4 \%$. This result is consistent with S-wave velocity structure beneath seismic stations near the caldera inferred from receiver functions. The differences are that the anomaly amplitude and thickness of S-wave low velocity layer is much larger and the distribution range is smaller than that obtained from seismic sounding. Compared with the P-wave velocity, S wave velocity is more sensitive to the melt or partial melt bodies in crust. The larger thickness and lower $\mathrm{S}$-wave velocity layer in crust near the caldera indicate that high-temperature magmatic material or magma reservoir may be still concentrated near the caldera, and its top is at $8-9 \mathrm{~km}$ depth.

The receiver function inversion result from different back azimuth directions shows great change of thickness of shallow low velocity layer, thicker in south and thinner in other directions. CBS station is located nearby a canyon which is starting at the caldera in south. The result indicates the sediment layer or low velocity fault zone along the canyon dips to the caldera. In analysis of volcanic earthquake types, we find many 
earthquakes occurred near the caldera having rich low frequency components at CBS station, the spectrum and waveforms are much like those of hybrid events or long-period events. But in other seismic stations near caldera, the seismic waveforms usually have similar characteristics as that of volcano-tectonic events. We think such phenomena at CBS is mainly caused by wave propagation effects in special velocity structure. For the CBS station, the recorded seismic waves from events occurred near in caldera usually propagate along canyon. If seismic waves have proper incident angles, the guide waves in fault zone or reverberation in thick low velocity sediment layer in south can be generated, which may enrich the low frequency components in seismic records. Therefore, if the seismic records at CBS station were used to analyze the type of volcanic earthquakes, such effects should be considered.
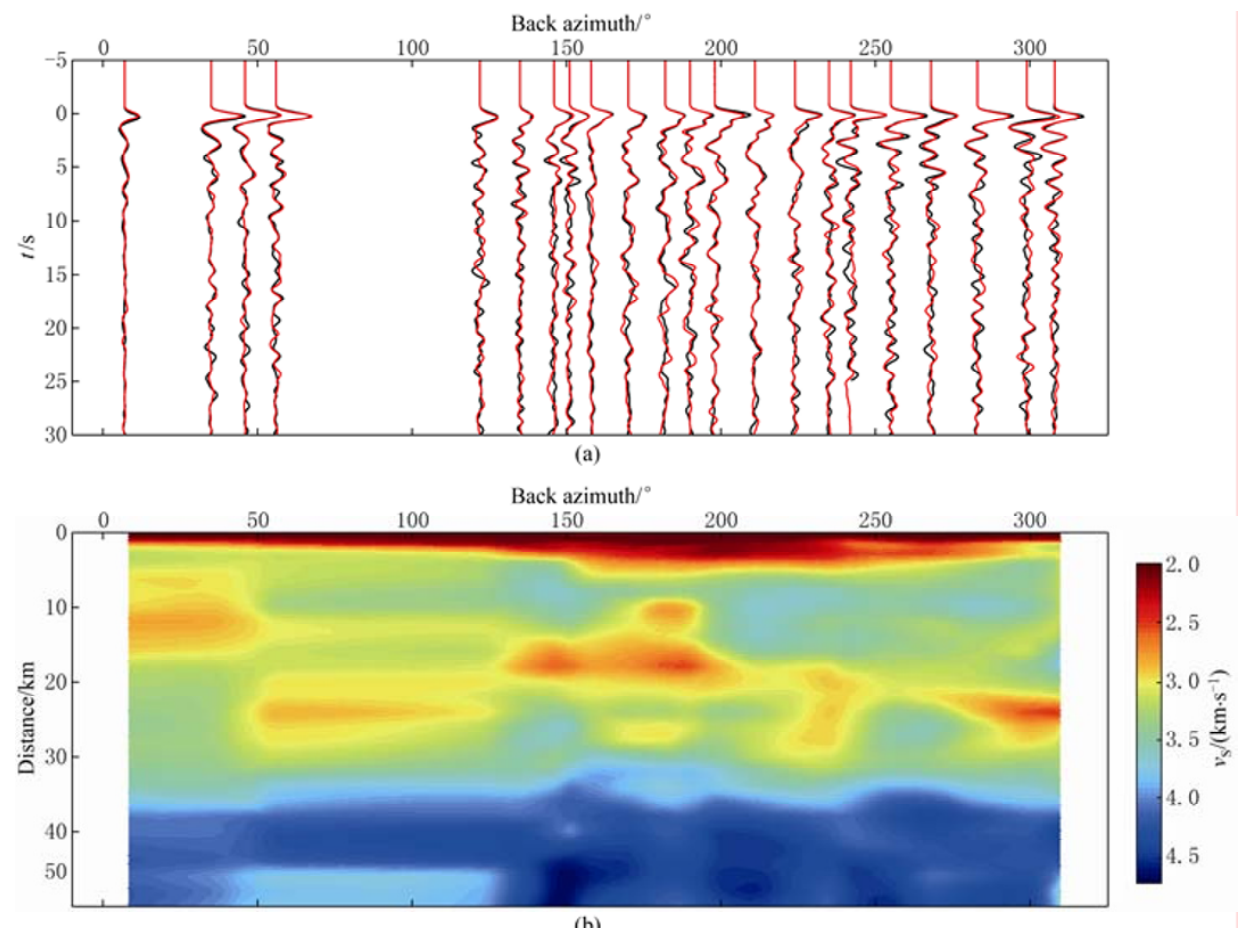

Figure 8 S-wave velocity structure at different back azimuth at CBS station. (a) Observed receiver functions (black lines) and synthetic receiver functions (red lines). (b) S-wave velocity structure in different back azimuth.

The Moho depth inverted from receiver function in different back azimuths at CBS shows about $4 \mathrm{~km}$ uplift in south direction (Figure $8 \mathrm{~b}$ ). If the crust thickness is $38 \mathrm{~km}$, and epicentral distance is $30^{\circ}-70^{\circ}$, the horizontal distance between CBS station and converted point of $\mathrm{P}-\mathrm{S}$ at Moho interface is about $7-10 \mathrm{~km}$. Considering the smooth velocity gradient in the crust-mantle transitional zone, the average depth of converted points should be less than $38 \mathrm{~km}$, so the horizontal distance between the CBS station and converted point may be within $6-9 \mathrm{~km}$. CBS station is located $4 \mathrm{~km}$ away from the north side of the caldera. For the receiver functions in $160^{\circ}-230^{\circ}$ back azimuth directions, the P-S converted points at Moho are located at the central or southern edge of the caldera. That means a local Moho uplift is located just beneath Tianchi caldera. It is different from results of seismic sounding (Zhang et al, 2002) and averaged receiver function inversion at different seismic stations, which considered Moho depth is the largest beneath Tianchi volcano. We consider that under the background of Moho depth gradually increases with shorter distance to the caldera, the Moho uplifts locally beneath the caldera. Considering the existence of smooth S-wave velocity gradient near the Moho and low velocity layer in crust in volcano region, we conclude that the local uplift of Moho beneath the caldera is related to mass exchanging channel between crust and upper mantle.

S-wave velocity structure from different stations shows there exist thick and distinct low velocity layers 
in crust near Tianchi caldera. Attenuation study shows that $Q_{\mathrm{c}}$ value is lower near the central area of the volcano, and relatively higher in the outskirts in Changbaishan (Wu et al, 2006). Considering the presence of high conductive bodies beneath the area from MT investigation (Tang et al, 2001), surface horizontal expansion and vertical uplifting from GPS measurement and leveling (Cui et al, 2007), and high seismicity centered at the caldera during 2002-2005 (Wu et al, 2005, 2007; Ming et al, 2006, 2007), we consider that the low velocity layer near the caldera is caused by the high temperature medium related to the magma chambers.

\section{Conclusions}

The low S-wave velocity layer widely exists in middle crust near Tianchi caldera. The thickness of low velocity layer in Changbaishan region usually increases with shorter distance to Tianchi caldera. The velocity of LVL decreases apparent near the caldera. Beneath WQD station, the low S-wave velocity layer is at $8-9 \mathrm{~km}$ depth with thickness of $20 \mathrm{~km}$. The lowest $\mathrm{S}$-wave velocity is about $2.5 \mathrm{~km} / \mathrm{s}$. The obvious low velocity structure in crust near the caldera may be related to high temperature material or partial melt magma reservoir.

Beneath CBS station, the thickness of low velocity layer near surface changes significantly for different back azimuths, with $4-5 \mathrm{~km}$ thick in south and $1-2 \mathrm{~km}$ in northeast. The changes of thickness of the low velocity layer near surface may be related to the shallow fault zone. Thick low velocity layer in south direction may be the main cause of relatively lower prominent frequency of volcanic earthquake waveform recorded by CBS station.

The Moho uplifts slightly beneath the caldera under the background of Moho depth gradually increase with shorter distance to the caldera. Considering the existence of low velocity layers in crust near the caldera and other geophysical investigation results, we conclude that there may exist a material exchange channel between upper mantle and magma reservoir in crust.

Acknowledgements This work was supported by National Key Project of Scientific and Technical Supporting Programs Funded by Ministry of Science \& Technology of China (2006BAC01B04) and Joint Seismological Science Foundation of China (106023). Contribution No. is 09FE3006 of Institute of Geophysics, China Earthquake Administration. We thank Yan Wen and Guoming Liu for providing seismic data of CBS used in this study.

\section{References}

Cui D X, Wang Q L, Li K, Wang W P and Hu Y X (2007). Analysis of recent deformation of Changbaishan Tianchi volcano. Chinese J Geophys 50(6): 1731-1 739 (in Chinese with English abstract).

Darbyshire F A, Priestley K F, White R S and Stefanaaon R (2000). Crustal structure of central and northern Iceland from analysis of teleseismic receiver functions. Geophys J Int 143: 163-184.

Hetland E A, Wu F T and Song J L (2004). Crustal structure in the Changbaishan volcanic area, China, determined by modeling receiver functions. Tectonophysics 386: 157-175.

Kennent B L N (1983). Seismic Wave Propagation in Stratified Media. Cambridge University Press, New York, 99-157.

Liu Q Y, Li S C, Shen Y and Chen J H (1997). Broadband seismic array study of the crust and upper mantle velocity structure beneath Yunhuai basin and its neighboring region. Chinese J Geophys 40(6): 763-771 (in Chinese with English abstract).

Liu R X, Li J T, Wei H Q, Xu D M and Zheng Q S (1992). Volcano at Tianchi Lake, Changbaishan Mt.-A modern volcano with potential danger of eruption. Chinese J Geophys 35(5): 661-664 (in Chinese with English abstract).

Liu R X, Wei H Q, Li J T, Yang Q F and Xu D M (1998). The Recent Eruption of Tianchi Volcano, Changbaishan. Science Press, Beijing, 1-13 (in Chinese).

Ming Y H, Su W and Fang L H (2006). A preliminary study of the types of volcanic earthquakes and volcanic activity at the Changbaishan Tianchi volcano. Earthquake Research in China 20(3): 286-294.

Ming Y H, Wu J P, Su W, Fang L H and Wang W L (2007). Harmonic-spectral event at Changbaishan Tianchi Volcano. Seismology and Geology 29(3): 492-501 (in Chinese with English abstract).

Owens T J, Zandt G and Taylor S R (1984). Seismic evidence for an ancient rift beneath the Cumberland Plateau, Tennessee: A detailed analysis of broadband teleseismic P waveforms. J Geophys Res 89: 7 783-7 795.

Tang J, Deng Q H, Zhao G Z, Li W J, Xuan F, Gin G W, Bai D H, Zhan Y, Liang J G, Pu X H, Wang J J, Li G S, Hong F, Ma Z M and Chen F X (2001). Electric conductivity and magma chamber at the Tianchi volcano area in Changbaishan Mountain. Seismology and Geology 23(2): 191-200 (in Chinese with English abstract).

Wei H, Hong H, Sparks R, Joseph S W and Han B (2004). Potential hazards of eruptions around the Tianchi caldera lake, China. Acta Geologica Sinica 78(3): 790-794.

Wu J P, Ming Y H and Wang C Y (2001). S wave velocity structure beneath digital seismic stations of Yunnan Province inferred from teleseimic receiver function modeling. Chinese J Geophys 44(2): 223-232.

Wu J P, Ming Y H, Zhang H R, Liu G M, Fang L H, Su W and Wang W L (2007). Earthquake swarm activity in Changbaishan Tianchi volcano. Chinese J Geophys 50(4): 938-946.

Wu J P, Ming Y H, Zhang H R, Su W and Liu Y M (2005). Seismic activity at the Changbaishan Tianchi volcano in the summer of 2002. Chinese $J$ Geophys 48(3): 684-691.

Wu J, Jiao W, Ming Y and Su W (2006). Attenuation of Coda waves at the Changbaishan Tianchi volcanic area in Northeast China. PAGEOPH 163: 1351-1368.

Wu Q J and Zeng R S (1998). The crustal structure of Qinghai-Xizang Plateau inferred from broadband teleseismic waveform. Chinese J Geophys 41(5): 669-679 (in Chinese with English abstract).

Xie G H and Wang J W (1988). Petrochemistry and Sr, Nd, Pb-isotopic geochemistry of cenozoic volcanic rocks, Changbaishan area, northeast China. Acta Petrologica Sinica 4(4): 1-12 (in Chinese with English abstract).

Zhang X K, Zhang C K, Zhao J R, Yang Z X, Li S L, Zhang J S, Liu B F, Chen S X, Sun G W and Pan S Z (2002). Deep seismic sounding investigation into the deep structure of the magma system in Changbaishan-Tianchi volcano region. Acta Seismologica Sinica 15(2): 143-151 (in Chinese with English abstract). 